Review Article

\title{
Surgical strategy for locally advanced gastric cancer.
}

\author{
Thakur Binay, Devkota Mukti, Bishal Sapkota \\ Department of Surgical Oncology, Thoracic Surgery Unit. BP Koirala Memorial Cancer Hospital, Bharatpur, Nepal.
}

\begin{abstract}
Gastric cancer is endemic in China, Japan, Korea, Brazil and Former Soviet Union. Patients are diagnosed usually in locally advanced stage. Endoscopy, PET-CT, Endoscopic ultrasound and staging laparoscopy are the tools for proper evaluation of such patients. Locally advanced gastric cancer ( $T 2-4 \mathrm{NO}$ or $\mathrm{T}$ any $\mathrm{N}+$ ) requires multimodality treatment including surgery. Surgical strategy requires gastrectomy with D2 nodal dissection.
\end{abstract}

Keywords: Gastric cancer; D2 lymphadenectomy; Gastrectomy.

\section{Introduction:}

Gastric cancer is rampant in many countries around the world. The incidence of gastric cancer is much higher in China than in any other country. In Japan, it remains the most common type of cancer among men. The incidence of gastric cancer, however, has been declining globally since World War II and it is one of the least common cancers in North America. By some estimates, it is the fifth most frequently diagnosed cancer and the third leading cause of death from cancer worldwide. In 2017 , an estimated 28,000 people will be diagnosed and 17,750 peoplez will eventually die of their disease in the United States. Non-cardia gastric cancer shows marked geographic variation with countries such as Japan, Korea, China, Taiwan, Costa Rica, Peru, Brazil, Chile, and the former Soviet Union.

In Japan (and in a limited fashion in Korea) where screening is performed widely, early detection is often possible. In other parts of the world, it continues to pose a major challenge for health care professionals.

Therefore, patients are diagnosed mostly in locally advanced stage. By definition, locally advanced cancer stands for T2-4N0 or N+ tumors.

Survival outcomes differ considerably between Eastern and Western populations, 4with better overall survival reported in Eastern series. Many authors have sought explanations for this finding based on the following: stage migration,5differences in tumor biology, or differences in treatment. Surgical treatment differs in that extended lymph node dissection is routinely practiced in Asian countries, ${ }^{6,7}$ resulting in greater lymph node retrieval. Whether this leads to stage migration or to a direct therapeutic effect has yet to be resolved. Furthermore, adjuvant therapy differs between the two regions.

Junctional tumors have a various approach, therefore only the tumors, which are, located more than $2 \mathrm{~cm}$ distal to GE Junction (Siewert type - III/ body and antrum) will be discussed here.

\section{Work-up and Staging}

Clinical staging has greatly improved with the availability of diagnostic modalities such as endoscopic ultrasound (EUS), CT, PET/ CT, MRI, and laparoscopic staging. ${ }^{8-10}$ EUS is indicated for assessing the depth of tumor invasion. However, the diagnostic accuracy of EUS is operator dependent, ranging from $57 \%$ to $88 \%$ for T staging and $30 \%$ to $90 \%$ for $\mathrm{N}$ staging. ${ }^{12}$ EUS is also helpful to identify $\mathrm{T} 1$ tumors for potential endoscopic approaches.

CT scan is routinely used for preoperative staging. It has an overall accuracy of $43 \%$ to $82 \%$ for T staging. Combined PET/CT imaging, on the other hand, has several potential advantages over PET scan alone. PET/ CT has a significantly higher accuracy in preoperative staging (68\%) than PET (47\%) or CT (53\%) alone.

Laparoscopic staging can detect occult metastases. In a study conducted by Memorial Sloan Kettering Cancer Center, 657 patients with potentially resectable gastric adenocarcinoma underwent laparoscopic staging over a period of 10 years. ${ }^{14}$ Distant metastatic disease (M1) was

\section{Correspondence}

Dr Binay Thakur MD, PhD, Senior Consultant, Dept. of Surgical Oncology

BP Koirala Memorial Cancer Hospital, Bharatpur, e-mail: binaythakur@hotmail.com 
detected in $31 \%$ of the patients.

In summary Routine work up includes upper GI endoscopy, CT of chest/ abdomen/ pelvis, CT/ PET if no evidence of distant metastases and EUS.

\section{Surgery}

In 2014, Japanese Gastric Cancer Association (JGCA) ${ }^{15}$ published Version 4 of the Japanese Gastric Cancer Treatment Guidelines. The English version was published in 2017. According to JGCA. Surgery has been classified as follows:

\section{Curative surgery}

Standard gastrectomy: Standard gastrectomy is the principal surgical procedure performed with curative intent. It involves resection of at least twothirds of the stomach with a D2 lymph node dissection.

Non-standard gastrectomy: In non-standard gastrectomy, the extent of gastric resection and/or lymphadenectomy is altered according to tumor stages.

Modified surgery: The extent of gastric resection and/or lymphadenectomy is reduced (D1, D1+, etc.) compared to standard surgery.

Extended surgery: (1) Gastrectomy with combined resection of adjacent involved organs. (2) Gastrectomy with extended lymphadenectomy exceeding D2.

\section{Non-curative surgery}

Palliative surgery: Serious symptoms such as bleeding or obstruction may develop in a patient with advanced/ metastatic gastric cancer. Surgery to relieve symptoms may then be considered an option, and palliative gastrectomy or gastrojejunostomy is selected depending on the resectability of the primary tumor and/or surgical risks.

Extent of gastric resection may vary from distal gastrectomy (Stomach resection including the pylorus. The cardia is preserved. In the standard gastrectomy, twothirds of the stomach is resected) to total gastrectomy (Total resection of the stomach including the cardia and pylorus).

Resection margin: A sufficient resection margin should be ensured when determining the resection line in gastrectomy with curative intent. Proximal margin of at least $3 \mathrm{~cm}$ is recommended for T2 or deeper tumors with an expansive growth pattern (types 1 and 2) and 5 $\mathrm{cm}$ for those with an infiltrative growth pattern (types 3 and 4). When these rules cannot be observed, it is advisable to examine the proximal resection margin by frozen section. For tumors invading the esophagus, a $5-\mathrm{cm}$ margin is not necessarily required, but frozen section examination of the resection line is desirable to ensure an $\mathrm{R} 0$ resection.

Anatomical definitions of lymph node stations and concept of nodal dissection:

Regional nodes for gastric cancer have been named as shown in Table 1.

\begin{tabular}{|c|c|}
\hline Nr. & Definition \\
\hline 1 & $\begin{array}{l}\text { Right paracardial LNs, including those along the } \\
\text { first branch of the ascending limb of the left gas- } \\
\text { tric artery }\end{array}$ \\
\hline 2 & $\begin{array}{l}\text { Left paracardial LNs including those along the } \\
\text { esophagocardiac branch of the left subphrenic ar- } \\
\text { tery }\end{array}$ \\
\hline $3 a$ & $\begin{array}{l}\text { Lesser curvature LNs along the branches of the left } \\
\text { gastric artery }\end{array}$ \\
\hline $3 b$ & $\begin{array}{l}\text { Lesser curvature LNs along the } 2^{\text {nd }} \text { branch and dis- } \\
\text { tal part of the right gastric artery }\end{array}$ \\
\hline $4 \mathrm{sa}$ & $\begin{array}{l}\text { Left greater curvature LNs along the short gastric } \\
\text { arteries (perigastric area) }\end{array}$ \\
\hline $4 \mathrm{sb}$ & $\begin{array}{l}\text { Left greater curvature LNs along the left gastro- } \\
\text { epiploic artery (perigastric area) }\end{array}$ \\
\hline $4 \mathrm{~d}$ & $\begin{array}{l}\text { Rt. greater curvature LNs along the } 2^{\text {nd }} \text { branch and } \\
\text { distal part of the right gastroepiploic artery }\end{array}$ \\
\hline 5 & $\begin{array}{l}\text { Suprapyloric LNs along the } 1 \text { st branch and proxi- } \\
\text { mal part of the right gastric artery }\end{array}$ \\
\hline 6 & $\begin{array}{l}\text { Infrapyloric LNs along the first branch and } \\
\text { proximal part of the right gastroepiploic artery } \\
\text { down to the confluence of the right gastroepiploic } \\
\text { vein and the anterior superior pancreatoduodenal } \\
\text { vein }\end{array}$ \\
\hline 7 & $\begin{array}{l}\text { LNs along the trunk of left gastric artery between } \\
\text { its root and the origin of its ascending branch }\end{array}$ \\
\hline $8 \mathrm{a}$ & $\begin{array}{l}\text { Anterosuperior LNs along the common hepatic } \\
\text { artery }\end{array}$ \\
\hline $8 \mathrm{p}$ & Posterior LNs along the common hepatic artery \\
\hline 9 & Coeliac artery \\
\hline
\end{tabular}




\begin{tabular}{|c|l|}
\hline Nr. & \multicolumn{1}{|c|}{ Definition } \\
\hline 10 & $\begin{array}{l}\text { Splenic hilar LNs including those adjacent to the } \\
\text { splenic artery distal to the pancreatic tail, and } \\
\text { those on the roots of the short gastric arteries and } \\
\text { those along the left gastroepiploic artery proximal } \\
\text { to its } 1^{\text {st }} \text { gastric branch }\end{array}$ \\
\hline $11 p$ & $\begin{array}{l}\text { Proximal splenic artery LNs from its origin to } \\
\text { halfway between its origin and the pancreatic tail } \\
\text { end }\end{array}$ \\
\hline
\end{tabular}

11d Distal splenic artery LNs from halfway between its origin and the pancreatic tail end to the end of the pancreatic tail

12a Hepatoduodenal ligament LNs along the proper hepatic artery, in the caudal half between the confluence of the right and left hepatic ducts and the upper border of the pancreas

12b Hepatoduodenal ligament LNs along the bile duct, in the caudal half between the confluence of the right and left hepatic ducts and the upper border of the pancreas

12p Hepatoduodenal ligament LNs along the portal vein in the caudal half between the confluence of the right and left hepatic ducts and the upper border of the pancreas

13 LNs on the posterior surface of the pancreatic head cranial to the duodenal papilla

$14 \mathrm{v}$ LNs along the superior mesenteric vein

15 LNs along the middle colic vessels

$16 a 1$ Paraaortic LNs in the diaphragmatic aortic hiatus

16a2 Paraaortic LNs between the upper margin of the origin of the celiac artery and the lower border of the left renal vein

16b1 Paraaortic LNs between the lower border of the left renal vein and the upper border of the origin of the inferior mesenteric artery

16b2 Paraaortic LNs between the upper border of the origin of the inferior mesenteric artery and the aortic bifurcation

17 LNs on the anterior surface of the pancreatic head beneath the pancreatic sheath

18 LNs along the inferior border of the pancreatic body

\begin{tabular}{|c|l|}
\hline Nr. & \multicolumn{1}{|c|}{ Definition } \\
\hline 19 & $\begin{array}{l}\text { Infradiaphragmatic LNs predominantly along the } \\
\text { subphrenic artery }\end{array}$ \\
\hline 20 & $\begin{array}{l}\text { Paraesophageal LNs in the diaphragmatic esoph- } \\
\text { ageal hiatus }\end{array}$ \\
\hline 110 & Paraesophageal LNs in the lower thorax \\
\hline 111 & $\begin{array}{l}\text { Supradiaphragmatic LNs separate from the esoph- } \\
\text { agus }\end{array}$ \\
\hline 112 & $\begin{array}{l}\text { Posterior mediastinal LNs separate from the } \\
\text { esophagus and the esophageal hiatus }\end{array}$ \\
\hline
\end{tabular}

Subtotal gastrectomy is the preferred approach for distal gastric cancers. This procedure has a similar surgical outcome compared to total gastrectomy although with significantly fewer complications. ${ }^{16}$ Adequate gastric resection (distal, subtotal, or total gastrectomy) to achieve negative microscopic margins $(4 \mathrm{~cm}$ or greater from the gross tumor) is preferred for resectable $\mathrm{T} 1 \mathrm{~b}$ T3 tumors. ${ }^{17} \mathrm{~T} 4$ tumors require en bloc resection of involved structures. Retrospective analyses have shown that more extensive lymph node dissection and analysis of 15 or more lymph nodes influences survival in patients with advanced gastric cancer. ${ }^{18,19}$ In the SEER database analysis that included 1377 patients diagnosed with advanced gastric cancer, patients who had more than 15 $\mathrm{N} 2$ nodes and more than $20 \mathrm{~N} 3$ nodes examined had the best long-term survival outcomes. ${ }^{18}$

\section{Extent of nodal dissection:}

Lymph node dissection can be classified into D1, D1+, D2, D2+ and D3. For locally advanced gastric cancer, Gastrectomy with D2 lymph node dissection is the standard treatment for curable gastric cancer in eastern Asia. In the West, D2 lymph node dissection is considered a recommended but not a required procedure. However, there is uniform consensus that removal of an adequate number of nodes (15 or greater) is beneficial for staging purposes.

Initial results from two large randomized trials performed in Western countries failed to demonstrate a significant survival benefit for D2 over D1 lymph node dissection. ${ }^{20,21}$ In the Dutch Gastric Cancer Group Trial, 711 patients who underwent surgical resection with curative intent were randomized to undergo either a D1 or D2 lymph node dissection. ${ }^{20}$ The postoperative morbidity ( $25 \%$ vs. $43 \%, \mathrm{P}<.001)$ and mortality ( $4 \%$ vs. $10 \%, P=.004)$ were higher for patients who underwent 
D2 lymph node dissection, with no difference in OS (30\% vs. $35 \%, P=.53$ ) between the two groups. In a subset analysis, patients with N2 cancer undergoing a D2 lymph node dissection showed a trend towards improved survival. Long-term follow-up data from the Dutch Gastric Cancer Group trial have confirmed a survival benefit for D2 lymph node dissection. The 15- year OS rates were $21 \%$ and $29 \%$, respectively, for the D1 and D2 group $(P=.34)$. D2 lymph node dissection was also associated with lower rates of $\operatorname{local}_{2}(12 \%$ vs. $22 \%)$ and regional recurrence (13\% vs.19\%). More importantly, gastric cancer-related death rate was significantly lower in the D2 group compared to the D1 group (37\% and $48 \%$, respectively).

The British Cooperative trial conducted by the Medical Research Council also failed to demonstrate a survival benefit for D2 over D1 lymph node dissection. The 5 -year OS rates were $35 \%$ and $33 \%$, respectively, for D1 and D2 lymph node dissections. In addition, the D2 lymph node dissection was associated with increased postoperative morbidity and mortality.

Both the Dutch and the MRC trials have been heavily criticized based on the following conditions: (1) poor quality control of both surgery and postoperative care, (2) high incidence of insufficient nodal dissection (noncompliance), and (3) adoption of a more aggressive D2 dissection by routine use of pancreatico-splenectomy. In a randomized controlled trial (JCOG9501), Japanese investigators comparing D2 lymph node dissection alone with D2 lymph node dissection with para-aortic nodal dissection (PAND) in patients undergoing gastrectomy for curable gastric cancer (T2b, T3, or T4) reponted a postoperative mortality rate of $0.8 \%$ in each arm. The final results of this study showed that D2 lymph node dissection with PAND does not improve survival rate, compared to D2 lymph node dissection alone. The 5-year OS rates were $70.3 \%$ and $69.2 \%$, respectively. There were also no significant differences in the relapse-free survival (RFS) rates between the two groups. ${ }^{24}$ In a post-hoc subgroup analysis, among patients with pathologically negative nodes, the survival rates were better for patients who underwent D2 lymph node dissection plus PAND than those who were assigned to D2 lymph node dissection alone. In patients with metastatic nodes, the survival rates were worse for those assigned to D2 lymph node dissection plus PAND. However, the investigators of this study caution that these results from post-hoc analysis could be false positive due to multiple testing, and the survival benefit of D2 lymph node dissection with PAND in patients with node- negative disease needs to be clarified in further studies. The investigators concluded that D2 lymph node dissection plus PAND should not be used to treat patients with curable gastric cancer (T2b, T3, or T4).

In a randomized phase II trial of D1 vs. D2 lymph node dissection conducted by the Italian Gastric Cancer Study Group in 267 patients with gastric cancer (133 patients allocated to D1 lymph node dissection and 134 patients allocated to D2 lymph node dissection), the morbidity and postoperative mortality rate were not significantly different between the two groups. ${ }^{25,26}$ In this study, pancreatectomy and splenectomy were not considered as a routine part of the D2 resection; the spleen and pancreas were removed only when indicated by the surgeon.

The overall mortality rate was $12 \%$ after D1 lymph node dissection vs. $17.9 \%$ after D2 lymph node dissection $(P=$ .183). The corresponding postoperative 30-day mortality rates were $3 \%$ and $2.2 \%$, respectively $(P=.722)$. At the median follow-up of 8.8 years, the 5 -year OS rates were $66.5 \%$ and $64.2 \%$ after D1 and D2 lymph node dissections, respectively $(\mathrm{P}=.695) .^{26} \mathrm{D} 2$ lymph node dissection was associated with a trend towards improved DSS in patients with advanced gastric cancer (pT2 T4) and positive lymph nodesed $59 \%$ vs. $38 \%$ for D1 lymph node dissection; $P=.055$ ).

Meta-analyses have confirmed that among patients who underwent D2 lymph node dissections, there was a trend toward improved survival and lower gastric cancerrelated mortality for patients who did not undergo resection of the spleen or pancreas, as well as for patients with T3 or T4 cancers. ${ }^{27-29}$

The role of splenectomy for complete resection of lymph node stations 10 and 11 has long been a controversial issue. Recently, the final results of an RCT (JCOG 0110) that compared splenectomy and spleen preservation in total gastrectomy have been re- ported with survival analysis. ${ }^{30}$ This is the largest RCT studying splenectomy in gastric cancer. It included 505 patients (splenectomy, 254; spleen preservation, 251) and demonstrated significant noninferiority of splenic preservation for the first time. The splenectomy group had higher morbidity $(P<.01)$ and larger blood loss $(P=.025)$ than the spleenpreserving group. The 5 -year OS rates were $75.1 \%$ and $76.4 \%$ in the splenectomy and spleen preservation groups, respectively, and the noninferiority of spleen 
preservation was demonstrated $(P=.025)$.

In total gastrectomy for proximal gastric cancer that does not invade the greater curvature, prophylactic splenectomy should be avoided; this is true not only for surgical safety but also for survival benefit.

Therefore, the recent guidelines emphasize that D2 lymph node dissection should be performed by experienced surgeons in high-volume centers. Prophylactic pancreatectomy and splenectomy should be avoided with D2 lymph node dissection. ${ }^{31,32}$

For total gastrectomy with D2 nodal dissection, levels 1,2,3,4,5,6,7,8a, 9,10,11p, 11d, 12a should be excised (Fig1). For distal gastrectomy with D2 dissection, levels, 1,3,4,5,6,7,8a, 9,11p, 12a should be excised. (Fig 2).

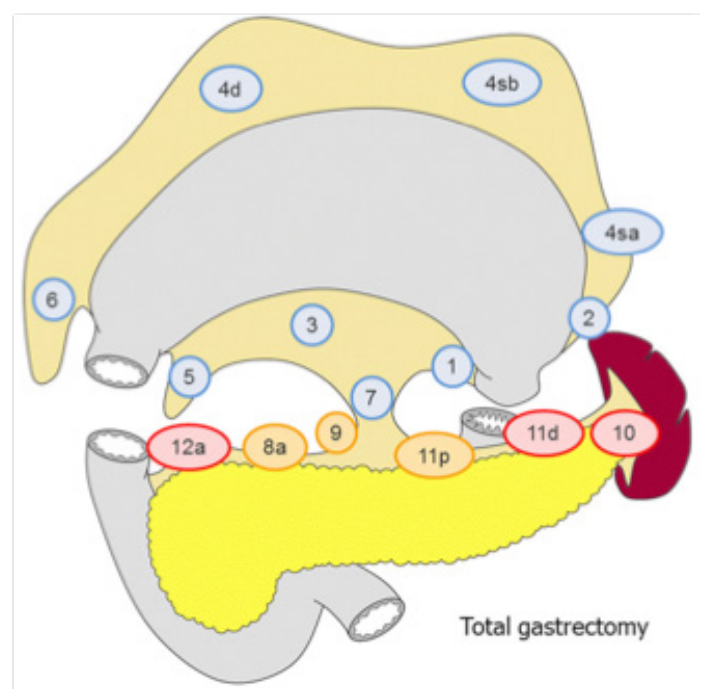

Fig. 1.

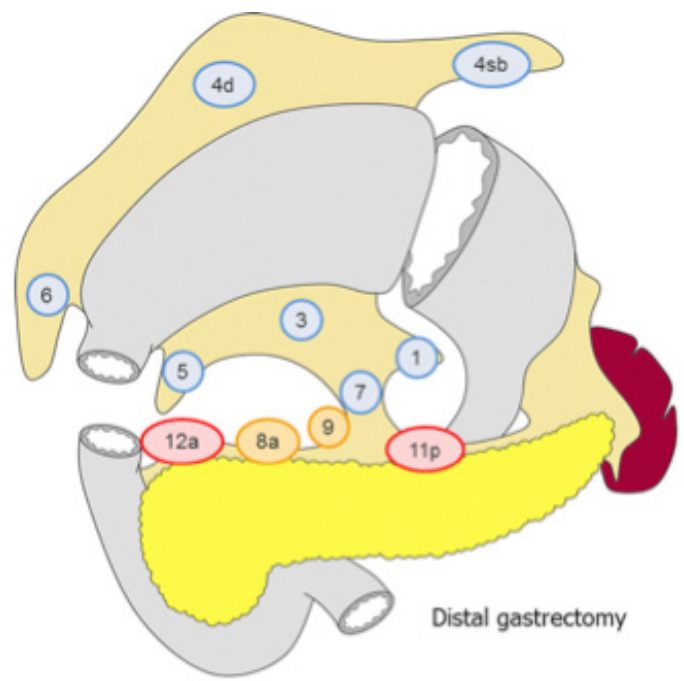

Fig 2.

\section{Laparoscopic Resection}

A metanalysis of 14 trials ( 1 RCT and 13 non- RCT) was performed. A total of 2596 patients (1328 - laparoscopic; 1268 - open) were included. Laparoscopic group showed lower intraoperative blood loss, lower analgesic consumption, and shorter time to first ambulation, flatus and oral intake, shorter hospitalization and lower postoperative morbidities. Oncological outcome, 3 and 5 -yr OS were similar. However, laparoscopic group had longer operative time. ${ }^{33}$

In a recent meta-analysis of 7 randomized controlled trials totaling 390 patients comparing laparoscopic versus open distal gastrectomies, the laparoscopic approach was found to have longer operative time but was also associated with less blood loss, fewer analgesics administered, faster recovery, and shorter postoperative hospital stay. ${ }^{34}$

\section{Postoperative Chemoradiation Therapy}

The landmark Intergroup trial SWOG 9008/INT-0116 investigated the effect of surgery plus postoperative chemoradiation on the ssurvival of patients with resectable gastric or EGJ. Median OS in the surgery only group was 27 months and was 36 months in the chemoradiation group $(P=.005)$. The chemoradiation group had better 3 -year OS (50\% vs. $41 \%$ ) and RFS rates $(48 \%$ vs. $31 \%)$ than the surgery only group. There was also a significant decrease in local failure as the first site of failure (19\% vs. $29 \%$ ) in the chemoradiation group. With more than 10 years of median follow-up, survival remains improved in patients with stage IB IV (M0) gastric cancer or EGJ adenocarcinoma treated with postoperative chemoradiation. ${ }^{36}$ In the INT-0116 trial, D2 lymph node dissection was not commonly performed and patients were not excluded on the basis of the extent of lymph node dissection. D0, D1, and D2 lymph node dissections were performed in $54 \%, 36 \%$, and $10 \%$ of patients, respectively.

\section{Postoperative chemoradiation vs. postoperative chemotherapy}

The results of a phase III trial (ARTIST trial) showed that postoperative chemoradiation with capecitabine and cisplatin did not significantly reduce recurrence after D2 lymph node dissection in patients with curatively resected gastric cancer $\left(n=458\right.$; stage IB IV, M0). ${ }^{37,38}$ At a median follow-up of 53 months, the estimated 3-year DFS 
rates were $78 \%$ and $74 \%$, respectively, for postoperative chemoradiation and chemotherapy $(P=.0862)$. After median follow-up duration of 7 years, the estimated 5 -year OS rates were $73 \%$ and $75 \%$, respectively, for postoperative chemotherapy and chemoradiation $(\mathrm{P}=$ $.484) .^{38}$ In the subgroup analysis of patients with positive pathologic lymph nodes, postoperative chemoradiation was associated with a statistically significant prolongation of 3-year DFS compared to chemotherapy alone (77.5\% and $72 \%$, respectively; $\mathrm{P}=.0365) .{ }^{37}$ However, this study demonstrated that postoperative treatment with capecitabine and cisplatin is feasible following a D2 lymph node dissection.

\section{Perioperative Chemotherapy}

The British Medical Research Council performed the first well-powered phase III trial (MAGIC trial) that evaluated perioperative chemotherapy for patients with resectable gastroesophageal cancer. ${ }^{39}$ In this trial, 503 patients were randomized to receive either perioperative chemotherapy (preoperative and postoperative chemotherapy) with ECF and surgery or surgery alone. Patients were randomized prior to surgery ( $74 \%$ of patients had gastric cancer; $69 \%$ in the surgery plus chemotherapy group and $66 \%$ in the surgery only group had undergone R0 resection). The majority of patients had T2 or higher tumors $(12 \%$ of patients had T1 tumors, $32 \%$ of patients had T2 tumors, and $56 \%$ of patients had T3 T4 tumors) and $71 \%$ of patients had node-positive disease. The perioperative chemotherapy group had a greater proportion of $\mathrm{T} 1$ and $\mathrm{T} 2$ tumors (51.7\%) and less advanced nodal disease (N0 or $\mathrm{N} 1 ; 84 \%)$ than the surgery group $(36.8 \%$ and $70.5 \%$, respectively). Perioperative chemotherapy significantly improved progression-free survival (PFS; $P<.001)$ and OS $(P=.009)$. The 5 -year survival rates were $36 \%$ among those who received perioperative chemotherapy and $23 \%$ in the surgery group.

But, only $41 \%$ had D2 dissection and in $41 \%$ lymphadenectomy status was unknown. Japanese surgeons would argue that perioperative chemotherapy or adjuvant chemoradiotherapy compensates for inadequate surgery.

\section{Postoperative Chemotherapy}

Asian, randomized, phase III studies (ACTS GC trial and CLASSIC trial) have documented survival benefit for postoperative chemotherapy after curative D2 lymph node dissection in patients with gastric cancer. ${ }^{40,41,42}$
The objective of the Japanese ACTS-GC trial was to examine the efficacy of adjuvant S-1 (tegafur, gimeracil, and oteracil) in stage II and III gastric cancer where 1034 patients were randomized to 12 months of oral S-1 or surgeryalone. ${ }^{40,41}$ Thesurgicalqualitycontrolwas excellent with all centers performing 100 cases annually; all but one patient underwent a D2 or D3 lymphadenectomy. The results of the trial regarding chemotherapy and surgery demonstrated an improvement in 5-year overall survival of $71.1 \%$ versus $61.1 \%$. This finding secured the place of postoperative chemotherapy with S-1 as a standard of care (recommendation category 1 ).

Additional evidence in support of postoperative chemotherapy was provided in 2012 by the CLASSIC trial conducted in South Korea, China, and Taiwan. ${ }^{42}$ In this trial, 1035 patients with stage II or III gastric cancer were randomized to XELOX (a combination of capecitabine and oxaliplatin) or surgery alone; significant prolongation of recurrence-free survival was shown in the XELOX arm.

\section{Significance of peritoneal lavage cytology}

In a metaanlysis by Jamel et $\mathrm{al}^{43}$, it was found, patients with positive cytology may have good prognosis following naeoadjuvant treatment if the cytology turns negative after treatment. They proposed a guideline:

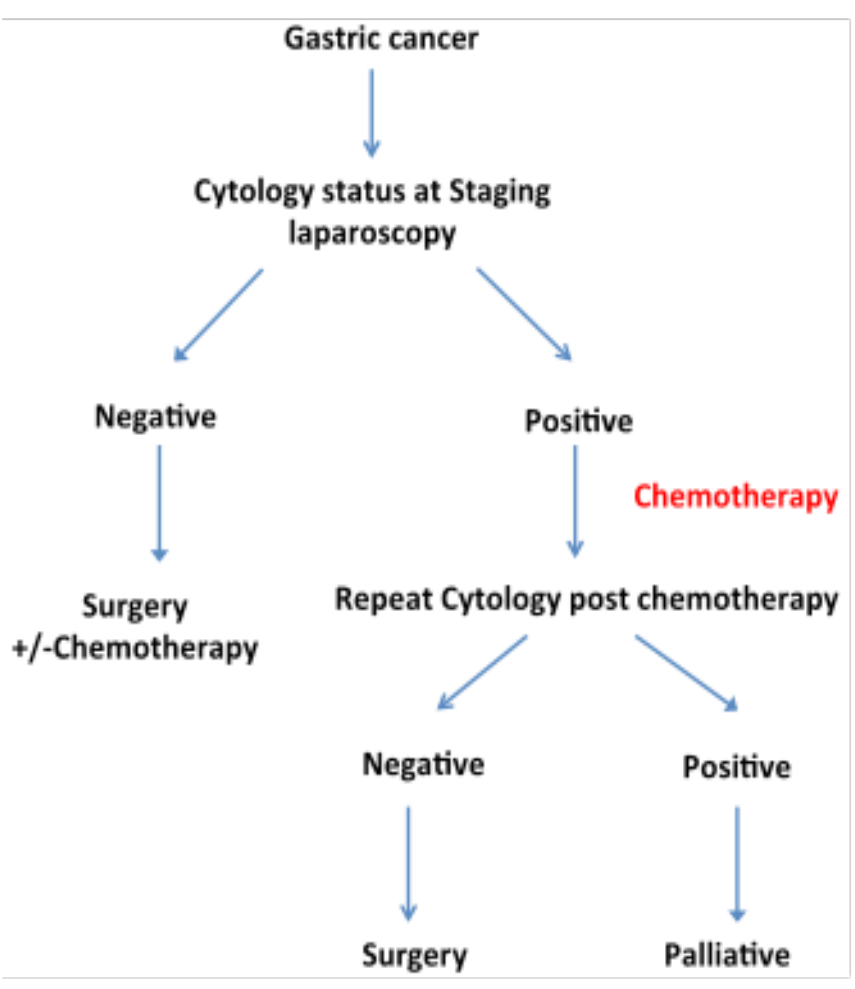




\section{Conclusion:}

At the time of diagnosis, patients are generally staged to have locally advanced disease except in the scenario of a National protocol for routine screening. In a resectable non metastatic disease, D2 gastrectomy not only stages the disease adequately but also improves overall and disease free survival. Therefore, D2 gastrectomy should be surgical procedure of choice. Extent of resection (distal vs. total gastrectomy) depends upon the location of tumor and if more than $4 \mathrm{~cm}$ of proximal tumor free margin can be achieved, distal gastrectomy has to be considered. Laparoscopic distal gastrectomy may be considered if the expertise is available. Laparoscopic total gastrectomy is technically more challenging and may not be recommended as a general rule. Besides, routine pancreaticosplenectomy should be avoided.

Based on the available evidences, the simple algorithm of management of locally advanced gastric cancer (excluding Siewert type II lesions), would be as follows:

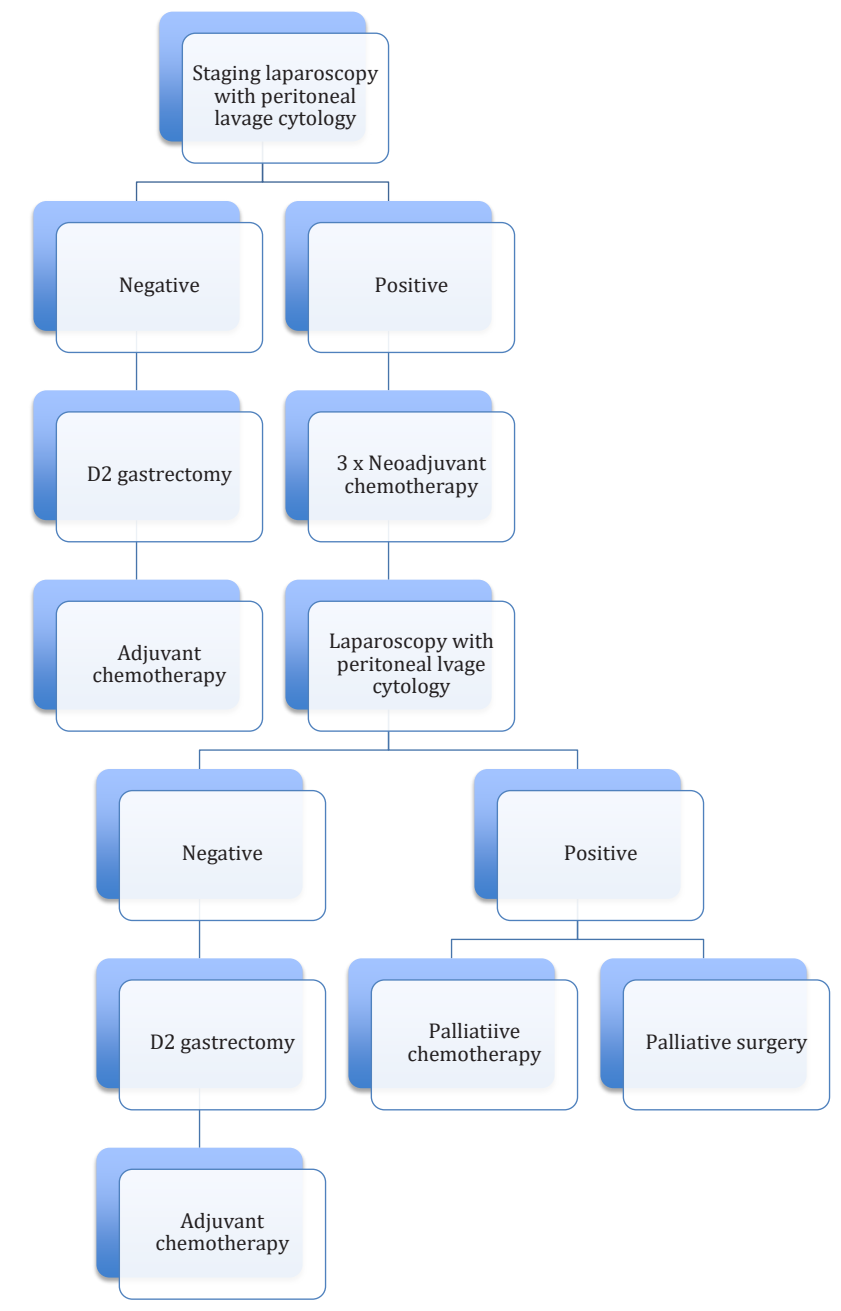

\section{References:}

1. GLOBOCAN 2012: Stomach Cancer: Estimated Incidence, Mortality and Prevalence Worldwide in 2012. Available at: http://globocan.iarc.fr/old/FactSheets/cancers/stomach-new.asp.

2. Siegel RL, Miller KD, Jemal A. Cancer Statistics, 2017. CA Cancer J Clin 2017; 67:7-30.

3. Corley DA, Buffler PA. Oesophageal and gastric cardia adenocarcinomas: analysis of regional variation using the Cancer Incidence in Five Continents database. Int J Epidemiol 2001; 30:1415- 1425.

4. Strong VE, Song KY, Park CH, et al. Comparison of gastric cancer survival following $\mathrm{R} 0$ resection in the United States and Korea using an internationally validated nomogram. Ann Surg 2010; 251:640-6.

5. Bickenbach K, Strong VE. Comparisons of gastric cancer treatments: East vs. West. J Gastric Cancer 2012; 12:55-62.

6. Sasako M, Saka M, Fukagawa T, et al. Surgical treatment of advanced gastric cancer: Japanese perspective. Dig Surg 2007; 24:101-7.

7. Yoon SS, Yang HK. Lymphadenectomy for gastric adenocarcinoma: should West meet East? Oncologist 2009; 14:871-82.

8. Abdalla EK, Pisters PWT. Staging and preoperative evaluation of upper gastrointestinal malignancies. Semin Oncol 2004; 31:513-529.

9. Kwee RM, Kwee TC. Imaging in local staging of gastric cancer: a systematic review. J Clin Oncol 2007; 25:2107-2116.

10. Weber WA, Ott K. Imaging of esophageal and gastric cancer. Semin Oncol 2004; 31:530-541.

11. Matsumoto Y, Yanai H, Tokiyama H, et al. Endoscopic ultrasonography for diagnosis of submucosal invasion in early gastric cancer. J Gastroenterol 2000; 35:326-331.

12. Cardoso R, Coburn N, Seevaratnam R, et al. A systematic review and meta-analysis of the utility of EUS for preoperative staging for gastric cancer. Gastric Cancer 2012; 15 Suppl 1:S19-26.

13. Rosenbaum SJ, Stergar H, Antoch G, et al. Staging and follow-up of gastrointestinal tumors with PET/ CT. Abdom Imaging 2006; 31:25-35.

14. Sarela AI, Lefkowitz R, Brennan MF, Karpeh MS. Selection of patients with gastric adenocarcinoma for laparoscopic staging. Am J Surg 2006; 191:134-138.

15. Japanese gastric cancer treatment guidelines 2014 (ver. 4). Japanese Gastric Cancer Associa- 
tion. Gastric Cancer. 2107; 20 (1): 1-19

16. Bozzetti F, Marubini E, Bonfanti G, et al. Subtotal versus total gastrectomy for gastric cancer: five-year survival rates in a multicenter randomized Italian trial. Italian Gastrointestinal Tumor Study Group. Ann Surg 1999; 230:170-178.

17. Ito H, Clancy TE, Osteen RT, et al. Adenocarcinoma of the gastric cardia: what is the optimal surgical approach? J Am Coll Surg 2004; 199:880-886.

18. Schwarz RE, Smith DD. Clinical impact of lymphadenectomy extent in resectable gastric cancer of advanced stage. Ann Surg Oncol 2007; 14:317-328.

19. Biondi A, D'Ugo D, Cananzi FC, et al. Does a minimum number of 16 retrieved nodes affect survival in curatively resected gastric cancer? Eur J Surg Oncol 2015; 41:779-786.

20. Hartgrink $\mathrm{HH}$, van de Velde $\mathrm{CJH}$, Putter $\mathrm{H}$, et al. Extended lymph node dissection for gastric cancer: who may benefit? Final results of the randomized Dutch gastric cancer group trial. J Clin Oncol 2004; 22:2069-2077.

21. Cuschieri A, Weeden S, Fielding J, et al. Patient survival after D1 and D2 resections for gastric cancer: long-term results of the MRC randomized surgical trial. Surgical Co-operative Group. Br J Cancer 1999; 79:1522-1530.

22. Songun I, Putter H, Kranenbarg EM, et al. Surgical treatment of gastric cancer: 15-year follow-up results of the randomised nationwide Dutch D1D2 trial. Lancet Oncol 2010; 11:439-449.

23. Sano T, Sasako M, Yamamoto $S$, et al. Gastric cancer surgery: morbidity and mortality results from a prospective randomized controlled trial comparing D2 and extended para-aortic lymphadenectomy--Japan Clinical Oncology Group study 9501. J Clin Oncol 2004; 22:2767-2773.

24. Sasako M, Sano T, Yamamoto S, et al. D2 lymphadenectomy alone or with para-aortic nodal dissection for gastric cancer. N Engl J Med 2008; 359:453462.

25. Degiuli M, Sasako M, Ponti A. Morbidity and mortality in the Italian Gastric Cancer Study Group randomized clinical trial of D1 versus D2 resection for gastric cancer. Br J Surg 2010; 97:643-649.

26. Degiuli M, Sasako M, Ponti A, et al. Randomized clinical trial comparing survival after D1 or D2 gastrectomy for gastric cancer. Br J Surg 2014; 101:2331.
27. Seevaratnam R, Bocicariu A, Cardoso R, et al. A meta-analysis of D1 versus D2 lymph node dissection. Gastric Cancer 201215 Suppl 1:S60-69.

28. Jiang L, Yang KH, Chen Y, et al. Systematic review and meta- analysis of the effectiveness and safety of extended lymphadenectomy in patients with resectable gastric cancer. Br J Surg 2014; 101:595-604.

29. El-Sedfy A, Dixon M, Seevaratnam R, et al. Personalized surgery for gastric adenocarcinoma: a meta-analysis of D1 versus D2 lymphadenectomy. Ann Surg Oncol 2015; 22:1820-1827.

30. Sano T, Sasako M, Mizusawa J, et al. Randomized controlled trial to evaluate splenectomy in total gastrectomy for proximal gastric carcinoma. Ann Surg 2016.

31. Yu W, Choi GS, Chung HY. Randomized clinical trial of splenectomy versus splenic preservation in patients with proximal gastric cancer. Br J Surg 2006; 93:559-563.

32. Csendes A, Burdiles P, Rojas J, et al. A prospective randomized study comparing D2 total gastrectomy versus D2 total gastrectomy plus splenectomy in 187 patients with gastric carcinoma. Surgery 2002; 131:401-407.

33. Zou ZH, Zhao LY, Mou TY, Hu YF, Yu J, Liu H, Chen H, Wu JM, An SL, Li GX.Laparoscopic vs open $\mathrm{D} 2$ gastrectomy for locally advanced gastric cancer: a meta-analysis.World J Gastroenterol. 2014 Nov 28; 20(44): 16750-64.

34. Deng Y, Zhang Y, Guo TK. Laparoscopy-assisted versus open distal gastrectomy for early gastric cancer: A meta-analysis based on seven randomized controlled trials. Surg Oncol 2015; 24(2): 71-7.

35. Macdonald JS, Smalley SR, Benedetti J, et al. Chemoradiotherapy after surgery compared with surgery alone for adenocarcinoma of the stomach or gastroesophageal junction. N Engl J Med 2001; 345:725730.

36. Smalley SR, Benedetti JK, Haller DG, et al. Updated Analysis of SWOG-Directed Intergroup Study 0116: A Phase III Trial of Adjuvant Radiochemotherapy Versus Observation After Curative Gastric Cancer Resection. J Clin Oncol 2012; 30:2327-2333.

37. Lee J, Lim do H, Kim S, et al. Phase III trial comparing capecitabine plus cisplatin versus capecitabine plus cisplatin with concurrent capecitabine radiotherapy in completely resected gastric cancer with D2 lymph node dissection: the ARTIST trial. J Clin 


\section{Nepalese Journal of Cancer (NIG)}

Oncol 2012; 30:268-273.

38. Park SH, Sohn TS, Lee J, et al. Phase III Trial to compare adjuvant chemotherapy with capecitabine and cisplatin versus concurrent chemoradiotherapy in gastric cancer: final report of the Adjuvant Chemoradiotherapy In Stomach Tumors trial, including survival and subset analyses. . J Clin Oncol 2015; 33:3130-3136.

39. Cunningham D, Allum WH, Stenning SP, et al. Perioperative chemotherapy versus surgery alone for resectable gastroesophageal cancer. N Engl J Med 2006; 355:11-20.

40. Sakuramoto S, Sasako M, Yamaguchi T, et al. Adjuvant chemotherapy for gastric cancer with S-1, an oral fluoropyrimidine. N Engl J Med 2007;357:18101820.
41. Sasako M, Sakuramoto S, Katai H, et al. Five-year outcomes of a randomized phase III trial comparing adjuvant chemotherapy with S-1 versus surgery alone in stage II or III gastric cancer. J Clin Oncol 2011; 29:4387-4393.

42. Noh SH, Park SR, Yang HK, et al. Adjuvant capecitabine plus oxaliplatin for gastric cancer after D2 gastrectomy (CLASSIC): 5-year follow-up of an open-label, randomised phase 3 trial. Lancet Oncol 2014; 15:1389-1396.

43. Jamel S, Markar SR, Malietzis G, Acharya A, Athanasiou T, Hanna GB. Prognostic significance of peritoneal lavage cytology in staging gastric cancer: systematic review and meta-analysis. Gastric Cancer. 2018 Jan;21(1):10-18. 